\title{
Blooms in the desert
}

The Arab world has a proud history of scholarship, but in recent decades it has neglected science. Now, against a backdrop of turmoil, a grassroots initiative hopes to restore the balance. Ehsan Masood reports.

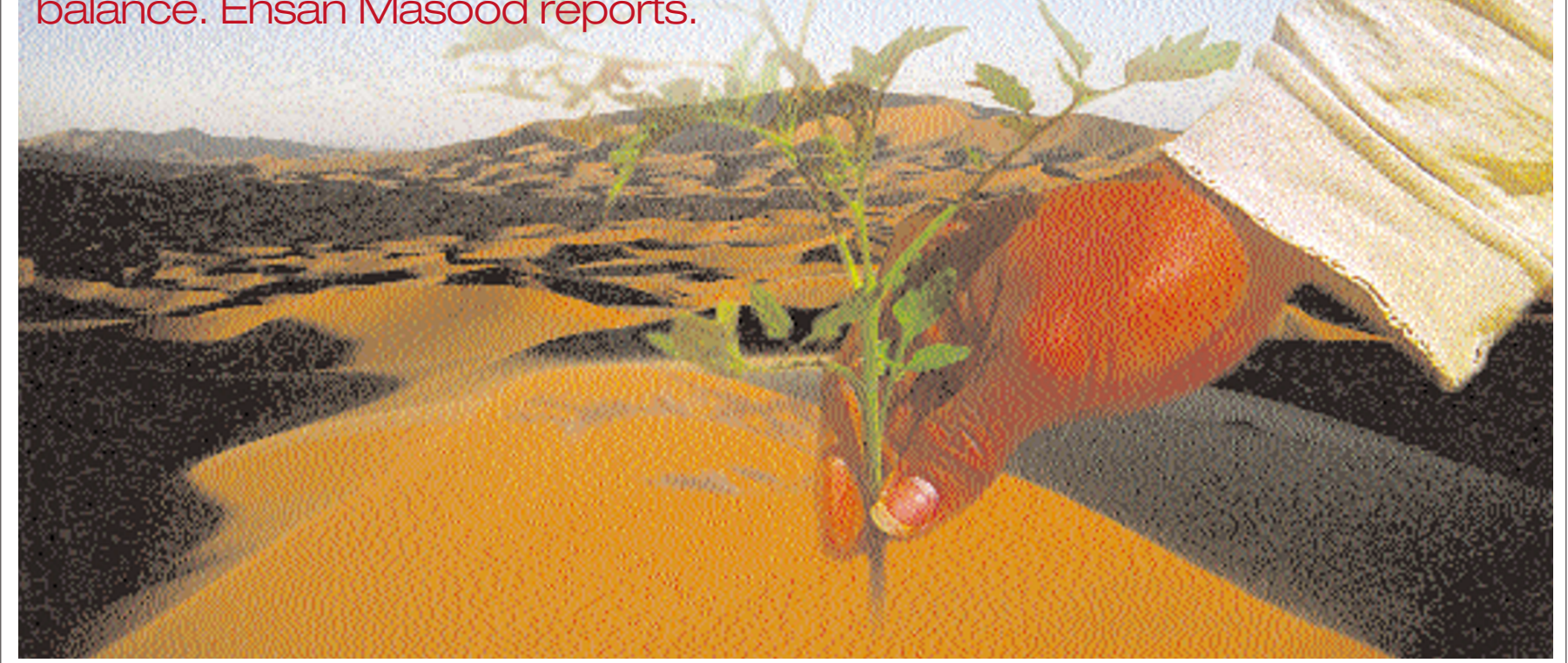

$\mathrm{T}$ hese are dark days for the Arab world. In many of its nations, standards of living are in decline. The PalestinianIsraeli conflict seems to get bloodier by the day. And further turmoil looms, as the US administration rattles its sabres at Iraq.

But for Arab scientists, at least, there are some chinks of light. Throughout the region, spending on research and development $(\mathrm{R} \& \mathrm{D})$ is on the rise - admittedly from a very low level. Later this month, scientists will meet in Sharjah, one of the United Arab Emirates, to set the agenda for a foundation that plans to award peer-reviewed grants to the region's researchers. There is also talk of establishing a fund to build scientific capacity across the entire family of Muslim nations.

There is just cause for optimism, says Egyptian-born Ahmed Zewail of the California Institute of Technology, who won the 1999 Nobel Prize in Chemistry. "But countries in the Arab world can and must do much more," he says. "They have both the money and the human resources."

A thousand years ago, Arab science led the world. While Europe languished in the Dark Ages, Arab scholars were pioneering developments in algebra and the study of modern astronomy. But today, the region is - for the most part - a scientific desert. In some states, oil wealth has allowed the construction of fabulous cities, magnificent mosques and sumptuous shopping malls. But little scientific infrastructure has emerged. Collectively, the Arab nations spend only $0.15 \%$ of their gross domestic product (GDP) on R\&D, well below the world average of $1.4 \%$.

But in recent years Arab states have realized that the petrodollars won't keep flowing for ever. Already, many of the region's nations are experiencing declines in GDP, and are starting to invest in science in the hope that it will underpin future economic development (see map, opposite).

\section{Fresh focus}

Take Oman: between 1992 and 1996, the latest period for which figures are available, its $\mathrm{R} \& \mathrm{D}$ budget increased by more than $83 \%$, whereas its per-capita GDP fell by some $10 \%$. Yemen, meanwhile, managed to increase its spending on R\&D by more than $55 \%$ over the same period, despite suffering a $65 \%$ fall in per-capita GDP. Total R\&D

\section{$\sqrt{\text { e're all working }}$ scientists. This} is not a body of people about to issue resolutions and declarations.

Abdalla Alnajjar expenditure in the Arab world amounted to US $\$ 782$ million in 1996 , compared with $\$ 579$ million in 1992. In this time, the number of full-time researchers grew by $8 \%$.

Given these trends, leaders of the nascent Arab Science and Technology Foundation (ASTF) hope that they are pushing at a door that is already ajar. Based in Sharjah, the foundation is a coalition of Arab scientists both those working in Arab nations, and expatriates who have built their careers in the West. It aims to evolve into a pan-Arab funding body that will operate like a Western granting agency - with political independence and thorough peer review. "We want to raise the quality of research in Arab institutions, end the professional isolation of those Arab scientists who have few external links, and eventually infuse research fields with new talent," says Muhammad Garwan, director of the Center for Applied Physical

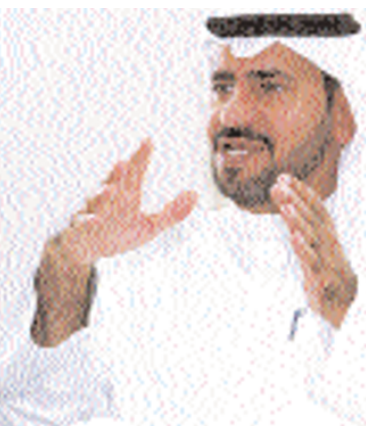


Sciences at the King Fahd University of Petroleum and Minerals in Dhahran, Saudi Arabia.

Launched in 2000, the foundation's goal is to nurture blooms in the desert of Arab science. Its progress to date has been underpinned by a US $\$ 6$-million donation from the ruler of Sharjah, Sheikh Sultan bin Mohammed Al Qassimi, a graduate in agricultural science. Unusually for a member of a Middle Eastern royal family, Al Qassimi promises to be hands-off, and not interfere in the foundation's day-to-day affairs.

The ASTF's board hopes to raise up to US $\$ 150$ million over the next five years. The government of the United Arab Emirates has already pledged support, although it has yet to announce a cash figure. Some 500 Arab scientists are meeting in Sharjah on 24-27 March to draw up priorities for the ASTF. Information technology, materials science, biotechnology, and research into energy and water supplies are expected to feature prominently.

\section{Turning the tide}

The ASTF's leaders are anxious not to second-guess the discussion in Sharjah they want the foundation's priorities to be set by the region's scientists, rather than be imposed by a few influential figures. But they are willing to point to some existing successful Arab scientific initiatives whose quality they hope to match.

The Arab sports of camel racing and falconry have spawned centres with generous funding and strong overseas collaborations.

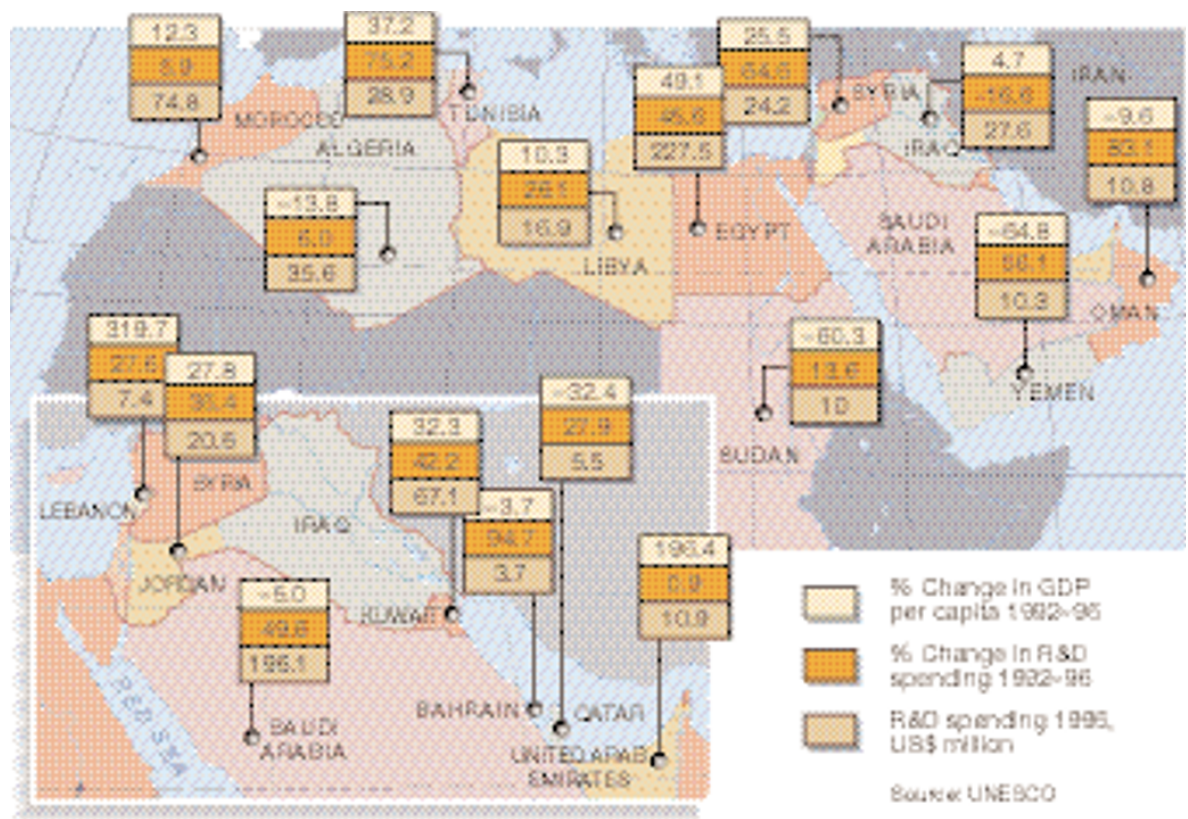

The Camel Reproduction Center in Dubai, for instance, is among a handful of labs in the world devoted to this field, and has links with the University of Cambridge. The National Avian Research Center in Abu Dhabi is another example of an institution with good overseas ties - it has chosen Carmarthen in Wales as the site for its Falcon Research Institute.

Arab countries also excel in desalination research. Middle Eastern states provide around $50 \%$ of the world's desalination capacity. The amount of water produced by this process in Arab countries is expected to double in the next 20 years. But research in this field is a good example of how international collaborations in science need to navigate the region's troubled politics.

As part of the Middle East peace process, the European Union, Israel, Japan, Oman, South Korea and the United States set up the Middle East Desalination Research Center in Muscat, Oman, in 1996. The centre's mandate is to spearhead collaborations between researchers in Arab countries and those abroad. But deteriorating relations with Israel have meant that researchers from Gulf countries are lukewarm about working with the centre. And US sanctions are preventing

\section{Still open for business}

The current 'war on terror' has placed an uncomfortable spotlight on Arabs living and studying in the West. But although fears of a backlash have driven some students away, the longterm prospects for Arab scientists wanting to reach out to their Western counterparts seem brighter.

Arab-Western scientific links have undoubtedly suffered some damage. Mujid Kazimi, a professor of nuclear engineering at the Massachusetts Institute of

Technology, says a "sizeable number" of students from the Gulf region left the United States after the terrorist attacks and did not return. Kazimi, who was born in Jerusalem, suspects that more Arab students might want to study closer to home in the future. Germany - shocked that Mohammed Atta, leader of the 11 September hijackers, studied at the Technical University of Hamburg has forced its universities to provide information about students, including their place of birth and religious background. Student representatives fear the move will fuel anti-Arab discrimination (see Nature 414, 478; 2001).

"It's more difficult for scientists from Muslim countries to find positions in Western institutions," says Atta-ur-Rahman, coordinatorgeneral of Comstech, the ministerial organization that promotes scientific cooperation among Muslim nations. Many postgraduates in the United States, he adds, are returning to their home countries instead of seeking postdoc opportunities abroad.

But scientists of Arab extraction living in the United States report few problems. Kazimi says that he sees no evidence of a reverse brain drain. "Arab and Muslim Americans, as well as those here on permanent visas, are not showing any signs of it," he says.

In the immediate aftermath of

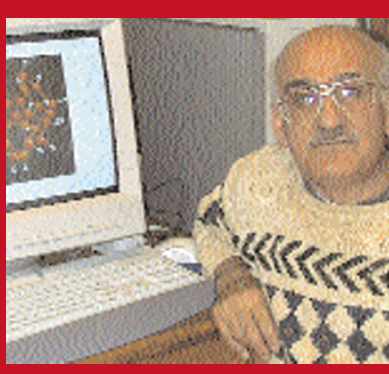

Munir Nayfeh: Arab scientists should have few travel worries.

last year's terrorist attacks, many Arab and Western scientists postponed visits to one another's labs. But things now seem to be returning to normal.

Palestinian-born Munir Nayfeh, professor of physics at the University of Illinois at Urbana-Champaign and president of Arab Scientists and Technologists Abroad, says that his links with Arab labs have been unaffected. He has just returned from a trip to Saudi Arabia, where scientists were anxious about visiting the West. Nayfeh tried to ease their fears: "I had a visitor in my lab from Damascus on 11 September. l've subsequently had visitors from Saudi Arabia and from Jordan; none have had any difficulty travelling or working."

Nevertheless, experts in immigration law warn Arab scientists visiting the United States to ensure that they have the correct paperwork. Suzanne Brummett, associate attorney with Paparelli and Partners in Irvine, California, says that researchers can expect tougher screening at airports and longer waits for visas. They should also keep their documents with them at all times - for students, this includes evidence of enrolment at a college or university. "Carry proof of immigration status," says Brummett. "If you don't, you could face $\mathbf{3 0}$ days in prison or a $\$ 200$ fine." 
participation by researchers from Libya.

Building and maintaining links with Western labs will be crucial to the ASTF. A significant part of the foundation's budget will be earmarked for research collaborations between scientists in Arab nations and those outside the region.

To establish such links, the ASTF is looking particularly to Arab researchers who have made their careers in the West. Shadia Rifai Habbal, a solar-terrestrial physicist at the University of Wales at Aberystwyth, is one such scientist. The ASTF presents "tremendous opportunities for both sides", she says. Habbal, who was born and educated in Syria, studied the 1999 solar eclipse with the help of researchers in that country.

There's an unmistakable sense of optimism among the ASTF's members. But talk to some of the older hands, and the magnitude of the task the ASTF is taking on becomes clear. Arab science has experienced several false dawns, as expert committees drew up strategies that have subsequently gathered dust on the shelves of the officials charged with their implementation.

Antoine Zahlan, formerly a professor of physics at the American University of Beirut and author of several books on Arab science policy, knows these frustrations first hand. Zahlan, who now lives in London, helped to draft a science strategy for the Arab League nearly two decades ago, which called on the league's members to invest at least $1 \%$ of their GDP in research. Few governments implemented any of its recommendations.

\section{More than just a building}

"The problem isn't necessarily a lack of money, or buildings, or trained PhDs," Zahlan says. Rather, there has been a failure to understand science's role in society and to realize that there's more to building scientific capacity than opening a gleaming new lab. Arab scientists complain that budgets are consumed by salaries and administration, leaving little for research. Experts also warn that official statistics on increases in science spending must be interpreted with caution, as these may include investments in higher education. "Even when you want to do research, the funds simply aren't there," says one senior Arab scientist, who asked not to be named.

Nader Fergany, director of the Almishkat Centre for Research in Cairo, an independent social-sciences research organization, blames the autocratic nature of many Arab societies for stifling scientific inquiry. "The prevailing social system is paternalistic, based on submission to, and fear of, authority," Fergany says. "Most Arabs lack the rudiments of functional literacy. An even greater majority has lost the ability to think critically and express themselves freely, and almost all are barred from effective participation in public affairs."

In such an environment, researchers tend

\section{Science veiled in secrecy}

Researching an article on science in the Arab world can be frustrating. Scientists in many Arab countries are reluctant to speak to foreign reporters on the phone. Correspondence by e-mail — which is easily monitored - is discouraged. Questions usually need to be faxed in advance. And don't bother asking about the repercussions of the events of 11 September 2001 - such enquiries will most probably be politely rebuffed. Ordinary jobbing scientists are afraid of saying anything that might upset the ruling authorities.

This culture of self-censorship has also hampered efforts to quantify the research activity of Arab countries. Even where information is willingly supplied, it is difficult to assess its accuracy. "In a few countries, the machinery to compile and analyse data simply does not exist," says one UN official. "They will

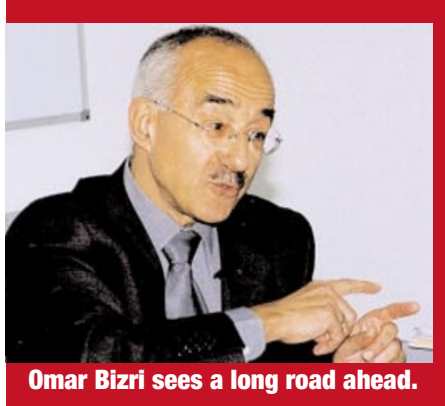
just guess at the numbers and jot down what they think is right."

Were it not for the persistence of Adnan Shihab-Eldin, former head of UNESCO's Cairo office, and Omar Bizri, head of the technology section at the UN Economic and Social Commission for Western Asia (ESCWA), based in Beirut, this article would be bereft of data. These two individuals were behind a 1998 study on science indicators in the Arab states, which relied heavily on dispatching emissaries to ministries and research labs with letters of recommendation to personal contacts. "In the Middle East, personal contact has always been more effective than formal contact in all transactions," says Shihab-Eldin, who is now director of research at the Organization of the Petroleum

\section{Exporting Countries in Vienna. "It is a cultural feature."}

To make future reports more reliable, ESCWA and UNESCO, with the help of the Organisation for Economic Co-operation and Development, aim to set up data-collection teams in each country, with properly trained personnel. Definitions of, for example, what constitutes spending on research and development also need to be agreed. At present, says Bizri, different countries have different interpretations. "A lot more work needs to be done."

to become inward-looking and wary of outsiders (see 'Science veiled in secrecy', above). Similarly, some funding agencies in Arab countries are reluctant to fund collaborations with foreign researchers, fearing that their governments will accuse them of leaking sensitive data to the West.

The ASTF's founders acknowledge the difficulties, but argue that they have already broken the mould by gathering together active researchers who understand the need for open scientific interchange. The foundation's origins lie in the frustrations of Arab scientists who want to do better research, says ASTF president Abdalla Alnajjar, a physicist and director of research at the University of Sharjah. "We want to be practical," he says. "We're all working scientists. This is not a body of people about to issue resolutions and declarations."

If the ASTF can engender a new culture of scientific openness in the Arab world, Western agencies seem likely to respond in kind. So far, most Western countries have few bilateral science agreements with Arab countries. But there is a desire to build stronger links.

\section{Positive action}

The United States has just one such agreement — with Egypt — in which \$2 million a year is allocated through the US Agency for International Development to Egyptian scientists for joint activities with US-based researchers. William Gaines, director of the Office of Science and Technology Cooperation in the State Department, hopes to increase the funds available for this collabo- ration to $\$ 3$ million, and to sign agreements with other Arab states. "Preliminary indications are positive," he says. Similarly, officials with the European Commission in Brussels are keen to use scientific projects to help forge closer links with Arab nations.

At the same time, there are also rumblings of the creation of a new research fund to foster scientific links among Muslim countries. Announced at the annual meeting of science ministers from the Organization of Islamic Countries (OIC) in Islamabad, Pakistan, last month, the precise scope of the fund remains unclear - but potentially, it could dwarf the ASTF. The fund is the brainchild of Atta-urRahman, coordinator-general of Comstech, which supports scientific cooperation among the OIC's member states. Rahman has a reputation for getting things done: last year, as Pakistan's science minister, he oversaw a 50-fold increase in his ministry's budget for R\&D projects.

Although it is too early to predict the impact of the ASTF and Rahman's proposed fund, it does seem that Arab science is at last beginning to emerge from its years in the desert. None too soon, say researchers, given that the region's future may depend on it developing a knowledge-based economy. "Countries that want to progress need to invest in their human resources," says Rahman. "The real wealth of a country is its people."

Ehsan Masood is director of communications at the sustainable development network LEAD International, based in London, and was formerly a reporter for Nature. www.astf.net 